\title{
The Effect of Growth Temperature on Wax Ester Composition in the Psychrophilic Bacterium Micrococcus cryophilus ATCC 15174
}

\author{
By N. J. RUSSELL ${ }^{1 *}$ AND J. K. VOLKMAN ${ }^{2}$ \\ ${ }^{1}$ Department of Biochemistry, University College, P.O. Box 78, Cardiff CF1 $1 X L$ \\ ' Organic Geochemistry Unit, School of Chemistry, University of Bristol, Cantock's Close, \\ Bristol BS8 1TS
}

(Received 19 October 1979)

\begin{abstract}
The wax ester and constituent fatty alcohol and fatty acid compositions of the psychrophilic bacterium Micrococcus cryophilus grown at 1 or $20^{\circ} \mathrm{C}$ have been analysed using packed column and capillary gas-liquid chromatography. The major wax esters were $\mathrm{C}_{36}, \mathrm{C}_{34}$ and $\mathrm{C}_{32}$, with a large percentage of mono- and di-unsaturated wax esters ( 91 to $99 \%$ of the total). When the growth temperature was lowered from 20 to $1{ }^{\circ} \mathrm{C}$ the average chain length of the wax esters decreased and their unsaturation increased. The average chain length of the saturated wax esters was less than that of the unsaturated wax esters. The fatty alcohols and fatty acids of the wax esters were mainly $\mathrm{C}_{18}$, with smaller amounts of $\mathrm{C}_{16}$, and were straight chain saturated and mono-unsaturated with cis double bonds at positions $\Delta 9$ and $\Delta 11$. The fatty alcohols had a shorter average chain length and were more saturated than the fatty acids, and contained a higher proportion of cis $\Delta 11$ unsaturated isomers. The combination of fatty alcohols and fatty acids in wax esters appeared to be random. The significance of these results is discussed in relation to the taxonomy of $M$. cryophilus, growth temperature-dependent membrane fluidity changes and the biosynthesis of wax esters.
\end{abstract}

\section{INTRODUCTION}

Wax esters are found throughout the plant and animal kingdoms (Kolattukudy, 1976) and in a few species of bacteria (Bryn et al., 1977; Albro, 1976), commonly in Acinetobacter species (Gallagher, 1971; Thorne et al., 1973; Fixter \& Fewson, 1974; Makula et al., 1975; Bryn et al., 1977). The presence of wax esters in Gram-negative cocci and their degree of unsaturation have been used in the classification of this group of bacteria (Bryn et al., 1977). However, it is not clear whether bacterial waxes are components of membranes. Wax esters have been detected in outer membrane fractions of Acinetobacter strain MJT/F5/199A (Thorne et al., 1973) and in the membranes (combined inner plus outer) of Micrococcus cryophilus (Russell, 1978a). It could be argued that the association with membranes is an artifact of isolation, although in $M$. cryophilus the wax ester composition is modified by changes in growth temperature (Russell, 1978a), which is typical of membrane lipids. On the basis of the results of experiments in which the wax ester content of Acinetobacter calcoaceticus grown in a chemostat under conditions of nitrogen or phosphorus limitation were studied, Fixter \& Fewson (1974) concluded that in this micro-organism the wax esters may be used as energy stores. There are too few studies, however, to draw any general conclusions about the function of wax esters in bacteria.

Our interest in bacterial wax esters is twofold. Firstly, wax esters have been found in aquatic sediments (Boon \& de Leeuw, 1979) and a knowledge of the acyl composition (e.g. 
chain length, position and geometry of double bonds) should be helpful in determining the origin of these lipids in such sediments. There is a paucity of information, however, on the structure of bacterial wax esters. Secondly, a detailed study of wax ester composition would provide important information as a preliminary to the study of the mechanism of biosynthesis of wax esters in bacteria. Although the synthesis of fatty alcohols has been studied in Escherichia coli (Naccarato et al., 1972; 1974), Mycobacterium tuberculosis (Wang et al., 1972) and Clostridium butyricum (Day et al., 1970), the complete synthesis of wax esters has not been studied in any bacterial species (Albro, 1976).

The present paper reports a detailed study of the wax ester composition of the psychrophilic bacterium Micrococcus cryophilus ATCC 15174; this is a Gram-negative coccus which resembles Acinetobacter species and contains a high proportion of wax esters in its lipid (Russell, 1974). The use of capillary gas-liquid chromatography has revealed the presence of positional isomers of unsaturated fatty alcohols and acids. The implications of this finding for the mechanism of their biosynthesis are discussed.

\section{METHODS}

Materials. Wax esters, fatty alcohols and fatty acids were obtained from Sigma or Nu-Chek Prep., Elysian, Mn. 56028, U.S.A. Reagents used were of the highest purity obtainable.

Maintenance and growth of cultures. Micrococcus cryophilus ATCC 15174 (the type strain) was grown at 1 or $20^{\circ} \mathrm{C}$ in a Casamino acids/salts medium (NM medium) (Russell, 1974) for at least two subcultures and four doubling times at the appropriate growth temperature prior to harvesting the bacteria for lipid extraction and analysis. The organism was maintained at $4{ }^{\circ} \mathrm{C}$ on $\mathrm{NM}$ medium containing $2 \%(\mathrm{w} / \mathrm{v})$ agar (Russell, 1974).

Lipid extraction and analysis. Bacteria were harvested in late-exponential phase and the total lipid was extracted with chloroform/methanol mixtures (see Russell, 1974). Wax esters were isolated from total lipid extracts by preparative thin-layer chromatography (t.l.c.) on $0.3 \mathrm{~mm}$ silica gel $\mathrm{H}$ (Merck) plates using light petroleum (b.p. 60 to $80^{\circ} \mathrm{C}$ )/diethyl ether/acetic acid $(85: 15: 1$, by vol.) as developing solvent. The wax ester band $\left(R_{F}\right.$ about 0.85$)$ was visualized with Rhodamine $6 \mathrm{G}(0.012 \%, \mathrm{w} / \mathrm{v})$, scraped off and the wax esters were eluted with three washes of diethyl ether. When required, wax fatty alcohols and wax fatty acids were prepared by saponification of the wax esters using $3 \mathrm{M}-\mathrm{KOH}$ in methanol. After dilution with water and acidification the products were extracted into light petroleum (b.p. 30 to $40{ }^{\circ} \mathrm{C}$ ) and treated with diazomethane. The resulting wax fatty alcohols and wax fatty acids (as methyl esters) were separated by preparative t.l.c., as above, using light petroleum (b.p. 60 to $80^{\circ} \mathrm{C}$ )/diethyl ether $(8: 2, \mathrm{v} / \mathrm{v})$ as developing solvent. Alternatively, wax fatty alcohols were extracted under alkaline conditions from saponification reaction mixtures, which were then acidified and wax fatty acids were extracted and esterified with diazomethane or $\mathbf{B F}_{3} /$ methanol $(14 \%, \mathrm{w} / \mathrm{w})$. In some experiments, wax esters were fractionated into saturated $\left(R_{F} 0.73\right)$, mono-unsaturated $\left(R_{F} 0.49\right)$ and di-unsaturated $\left(R_{F}, 0.36\right)$ wax esters by preparative argentation t.l.c. on $0.3 \mathrm{~mm}$ silica gel $\mathrm{HF}_{254+366}$ (type 60) plates containing $\mathrm{AgNO}_{3}(12.5 \%$ w/w) using hexane/diethyl ether $(9: 1, \mathrm{v} / \mathrm{v})$ as developing solvent.

Gas-liquid chromatography (g.l.c.). Wax esters were analysed directly with a Carlo Erba FTV 2151 gas chromatograph fitted with $12 \mathrm{~m} \times 0.3 \mathrm{~mm}$ (i.d.) or $20 \mathrm{~m} \times 0.3 \mathrm{~mm}$ (i.d.) wall-coated open tubular (WCOT) glass capillary columns coated with OV-1 according to the method of Grob et al. (1978). The use of the shorter column verified the absence of wax esters of chain length greater than $\mathrm{C}_{38}$. The carrier gas was helium at an inlet pressure of $0.9 \mathrm{kgf} \mathrm{cm}^{-2}\left(12 \mathrm{~m}\right.$ column) or $1.4 \mathrm{kgf} \mathrm{cm}^{-2}$ (20 m column) corresponding to a flow of about $1.5 \mathrm{ml} \mathrm{min}{ }^{-1}$. The oven temperature was programmed from 100 to $280^{\circ} \mathrm{C}$ at $4{ }^{\circ} \mathrm{C} \mathrm{min}-1$ and held isothermally at $280^{\circ} \mathrm{C}$ for 30 min to elute the $\mathrm{C}_{38}$ wax esters. A flame ionization detector was employed with injector and detector temperatures of $300^{\circ} \mathrm{C}$. Peak areas were measured manually by triangulation (peak height $\times$ peak width at half height) and by electronic integration using an Infratronics 308 computing integrator. All calculations were performed at least in triplicate and the average was used to calculate the results presented in Table 1. Equal flame ionization detector response factors were assumed for all the wax esters (Bryn et al., 1977).

Fatty acids (as methyl esters) and fatty alcohols (as acetates) derived from saponification of the wax esters were analysed by packed column g.l.c. using a Perkin-Elmer F33 gas chromatograph fitted with a flame ionization detector. The $1.5 \mathrm{~m} \times 5 \mathrm{~mm}$ (i.d.) glass columns were packed with $15 \%(\mathrm{w} / \mathrm{w})$ ethylene glycol succinate silicone (EGSS-X) on 80 to 100 mesh Chromosorb W AW (Supelco, Bellefont, Pa. 16823, U.S.A.). 
Separations were achieved isothermally at $190^{\circ} \mathrm{C}$ with detector and injector temperatures of $225^{\circ} \mathrm{C}$. Peak areas were measured using a Varian CDS III integrator, and agreed to within $2 \%$ with values obtained using capillary g.l.c.

Fatty acid methyl esters and fatty alcohols, both as trimethylsilyl ethers and acetate derivatives, were analysed on the $20 \mathrm{~m} \mathrm{OV}-1$ glass capillary column, as described for the wax ester samples (see above), except that a lower inlet pressure of $0.7 \mathrm{kgf} \mathrm{cm}^{-2}$ was used giving a flow of about $1 \mathrm{ml} \mathrm{min}^{-1}$. This column provided almost complete resolution for each pair of double-bond positional isomers and these could be co-injected with available authentic standards. Additional data on the double bond positions in the fatty acid methyl esters were obtained using a $100 \mathrm{~m} \times 0.3 \mathrm{~mm}$ (i.d.) WCOT glass capillary column coated with diethylene glycol succinate, operated isothermally at $170{ }^{\circ} \mathrm{C}$ with helium as the carrier gas. This capillary g.l.c. column provided a useful check on the identifications made, since the order of elution of the saturated and monounsaturated fatty acid methyl esters is the reverse of that on the apolar OV-1 columns.

Identification of double bond position by mild permanganate oxidation. The position of the double bond in the fatty acids and fatty alcohols deduced from co-injection on the capillary g.l.c. columns was confirmed using the $\mathrm{KMnO}_{4}$ oxidation procedure of Downing \& Greene (1968), as described previously (Russell, $1978 \mathrm{~b}$ ). Free fatty alcohols were oxidized efficiently by this procedure to produce dicarboxylic acid fragments by oxidation of the primary alcohol group to a carboxyl group, in addition to the oxidative cleavage of the double bond.

Infrared spectroscopy. The presence of trans unsaturated isomers was checked using infrared spectroscopy. Wax ester, fatty acid and fatty alcohol samples were spread as a thick film between the plates of $\mathrm{NaCl}$ cells and spectra were recorded using a Perkin-Elmer model 137B Infracord spectrometer operated at room temperature without any reference cell.

Combined capillary g.l.c./mass spectrometry. Mass spectra of the fatty acid methyl esters, fatty alcohols (as trimethylsilyl ethers and acetates) and wax esters were obtained using a Finnigan 4000 combined capillary g.l.c./quadrupole mass spectrometer linked to a laboratory PDP-8e computer system. Mass spectra were taken every $2 \cdot 2 \mathrm{~s}$ at an electron energy of $40 \mathrm{eV}$, electron current of $350 \mu \mathrm{A}$, accelerating voltage of $2 \mathrm{kV}$ and ion source temperature of $250^{\circ} \mathrm{C}$. A $20 \mathrm{~m} \times 0.3 \mathrm{~mm}$ (i.d.) glass capillary WCOT OV-1 column coupled directly to the ion source using glass-lined stainless steel tubing was used. The g.l.c. conditions were similar to those described above. The mass spectra obtained were compared with those of available standards and with those in the literature (Aasen et al., 1971; Spencer, 1979).

Melting point determinations. For each available wax ester standard (Sigma) at least three melting point determinations were made using capillary tubes; individual measurements agreed to within $1^{\circ} \mathrm{C}$.

\section{RESULTS}

\section{Wax ester composition}

The results of analyses of intact wax ester samples extracted from Micrococcus cryophilus grown at 1 or $20^{\circ} \mathrm{C}$ are summarized in Table 1 . The predominant wax esters in all samples were $\mathrm{C}_{36}, \mathrm{C}_{34}$ and $\mathrm{C}_{32}$, in order of decreasing abundance, with a large proportion being unsaturated. The degree of unsaturation of the wax esters increased as the growth temperature decreased. Bacteria grown at $20^{\circ} \mathrm{C}$ contained a higher proportion of saturated and mono-unsaturated wax esters and a lower proportion of di-unsaturated wax esters compared with bacteria grown at $1{ }^{\circ} \mathrm{C}$, which contained $<1 \%$ saturated wax esters. These differences were reflected in an increase in the wax ester unsaturation index [i.e. $(\%$ mono-unsaturated + $2 \times \%$ di-unsaturated) $/ 100$ ] from 1.41 for bacteria grown at $20{ }^{\circ} \mathrm{C}$ to 1.84 for bacteria grown at $1{ }^{\circ} \mathrm{C}$. These growth temperature-dependent changes in unsaturation did not appear to be associated with wax esters of a particular chain length. However, if the chain length of wax esters of bacteria grown at a particular temperature were studied, it was noticeable that the average chain length (as exemplified by the $\mathrm{C}_{36} / \mathrm{C}_{34}$ and $\mathrm{C}_{36} / \mathrm{C}_{32}$ ratios-see Table 1) was greater for the di-unsaturated than for the mono-unsaturated wax esters, which in turn had a greater average chain length than the saturated wax esters. The overall picture was complicated by the concomitant growth temperature-dependent chain length changes, the average chain length of all wax ester classes decreasing with a reduction in growth temperature. When the total wax esters were considered, the $C_{36} / C_{34}$ and $C_{36} / C_{32}$ ratios, calculated from the results in Table 1, decreased from 2.60 and 16.90 in bacteria grown at $20{ }^{\circ} \mathrm{C}$ to 1.57 and 7.92 in bacteria grown at $1{ }^{\circ} \mathrm{C}$. 


\title{
Table 1. Percentage composition of wax esters in Micrococcus cryophilus grown at 1 or $20^{\circ} \mathrm{C}$
}

\begin{abstract}
Wax esters were analysed by capillary g.l.c. as described in Methods, and amounts of wax esters are given as the mean areas of individual peaks ( \pm standard deviation) expressed as a percentage of the total area under the chromatogram. The number of cultures extracted is given by $n$. At least three analyses were performed on the wax esters of each culture. Wax esters are designated by "number of carbon atoms:number of double bonds'. $\mathbf{A}$ and $\mathbf{B}$ refer to the major peaks of each mono- and di-unsaturated wax ester of a particular chain length (see text and Fig. 1). 36/34 and 36/32 are the ratios of the percentages of wax esters of the chain lengths indicated within a class (saturated, monounsaturated, di-unsaturated).
\end{abstract}

\begin{tabular}{|c|c|c|c|c|c|c|}
\hline \multirow[b]{2}{*}{ Wax ester } & \multicolumn{3}{|c|}{ Growth at $1{ }^{\circ} \mathrm{C}(n=2)$} & \multicolumn{3}{|c|}{ Growth at $20^{\circ} \mathrm{C}(n=3)$} \\
\hline & $\begin{array}{c}\text { Composition } \\
(\%)\end{array}$ & $36 / 34$ & $36 / 32$ & $\begin{array}{c}\text { Composition } \\
(\%)\end{array}$ & $36 / 34$ & $36 / 32$ \\
\hline $\begin{array}{c}\text { Saturated } \\
30: 0 \\
32: 0 \\
34: 0 \\
36: 0 \\
38: 0 \\
\text { Others }\end{array}$ & $\begin{array}{c}\operatorname{tr} \\
0 \cdot 3 \pm 0 \cdot 4 \\
0 \cdot 4 \pm 0 \cdot 1 \\
0 \cdot 2 \pm 0 \cdot 0 \\
\operatorname{tr} \\
\operatorname{tr}\end{array}$ & & & $\begin{array}{l}0 \cdot 3 \pm 0 \cdot 1 \\
1 \cdot 2 \pm 0 \cdot 4 \\
3 \cdot 6 \pm 0 \cdot 9 \\
3 \cdot 2 \pm 1 \cdot 1 \\
0 \cdot 3 \pm 0 \cdot 3 \\
0 \cdot 4 \pm 0 \cdot 3\end{array}$ & & \\
\hline Total saturated & $0 \cdot 9$ & 0.50 & 0.67 & $9 \cdot 0$ & 0.89 & $2 \cdot 67$ \\
\hline $\begin{array}{l}\text { Mono-unsaturated } \\
30: 1 \Delta 9 \text { (A) } \\
30: 1 \Delta 11 \text { (B) } \\
32: 1 \Delta 9 \text { (A) } \\
32: 1 \Delta 11 \text { (B) } \\
34: 1 \Delta 9 \text { (A) } \\
34: 1 \Delta 11 \text { (B) } \\
36: 1 \Delta 9 \text { (A) } \\
36: 1 \Delta 11 \text { (B) } \\
38: 1 \Delta 9 \text { (A) } \\
38: 1 \Delta 11 \text { (B) } \\
\text { Others }\end{array}$ & $\begin{array}{c}0 \cdot 2 \pm 0 \cdot 1 \\
0 \cdot 2 \pm 0 \cdot 1 \\
1 \cdot 4 \pm 0 \cdot 9 \\
1 \cdot 5 \pm 0 \cdot 9 \\
8 \cdot 7 \pm 6 \cdot 9 \\
0 \cdot 6 \pm 0 \cdot 6 \\
2 \cdot 5 \pm 3 \cdot 0 \\
0 \cdot 1 \pm 0 \cdot 1 \\
\operatorname{tr} \\
\operatorname{tr} \\
0 \cdot 3 \pm 0 \cdot 2\end{array}$ & & & $\begin{array}{r}0 \cdot 5 \pm 0 \cdot 3 \\
0 \cdot 1 \pm 0 \cdot 0 \\
1 \cdot 9 \pm 0 \cdot 5 \\
0 \cdot 4 \pm 0 \cdot 1 \\
13 \cdot 8 \pm 0 \cdot 4 \\
2 \cdot 7 \pm 0 \cdot 6 \\
24 \cdot 6 \pm 3 \cdot 0 \\
4 \cdot 2 \pm 2 \cdot 6 \\
0 \cdot 9 \pm 0 \cdot 1 \\
0 \cdot 2 \pm 0 \cdot 0 \\
1 \cdot 0 \pm 0 \cdot 1\end{array}$ & & \\
\hline Total mono-unsaturated & $15 \cdot 5$ & $0 \cdot 28$ & 0.90 & $50 \cdot 3$ & 1.75 & $12 \cdot 52$ \\
\hline $\begin{array}{c}\text { Di-unsaturated } \\
32: 2 \text { (A) } \\
32: 2 \text { (B) } \\
34: 2 \text { (A) } \\
34: 2 \text { (B) } \\
36: 2 \text { (A) } \\
36: 2 \text { (B) } \\
38: 2 \text { (A) } \\
38: 2 \text { (B) } \\
\text { Others }\end{array}$ & $\begin{array}{c}2 \cdot 3 \pm 0 \cdot 6 \\
1 \cdot 6 \pm 0 \cdot 4 \\
9 \cdot 6 \pm 1 \cdot 5 \\
16 \cdot 4 \pm 1 \cdot 5 \\
41 \cdot 6 \pm 6 \cdot 4 \\
11 \cdot 8 \pm 4 \cdot 5 \\
\operatorname{tr} \\
\operatorname{tr} \\
0 \cdot 7 \pm 0 \cdot 1\end{array}$ & & & $\begin{array}{r}0.2 \pm 0 \cdot 0 \\
0.2 \pm 0 \cdot 0 \\
2 \cdot 8 \pm 0 \cdot 3 \\
2 \cdot 5 \pm 0 \cdot 7 \\
18 \cdot 1 \pm 2 \cdot 5 \\
15 \cdot 8 \pm 2 \cdot 9 \\
0.5 \pm 0 \cdot 2 \\
0.3 \pm 0.0 \\
0.6 \pm 0.0\end{array}$ & & \\
\hline Total di-unsaturated & $84 \cdot 0$ & $2 \cdot 05$ & $13 \cdot 69$ & $41 \cdot 0$ & $6 \cdot 40$ & $84 \cdot 75$ \\
\hline
\end{tabular}

Previous analyses of bacterial and other wax esters (e.g. Tulloch, 1975; Tagaki et al., 1976; Bryn et al., 1977) have employed conventional packed g.l.c. columns, which provide relatively poor separation of wax esters differing in their degree of unsaturation. Such wax esters were well separated by the capillary columns used here. In addition, the monounsaturated wax esters were resolved into two components (Fig. 1), A and B, due to the presence of both cis $\Delta 9$ and cis $\Delta 11$ isomers (see below). Compounds A are cis $\Delta 9$ wax esters; the double bond may be in the fatty alcohol or fatty acid, since, for instance, stearyl oleate 


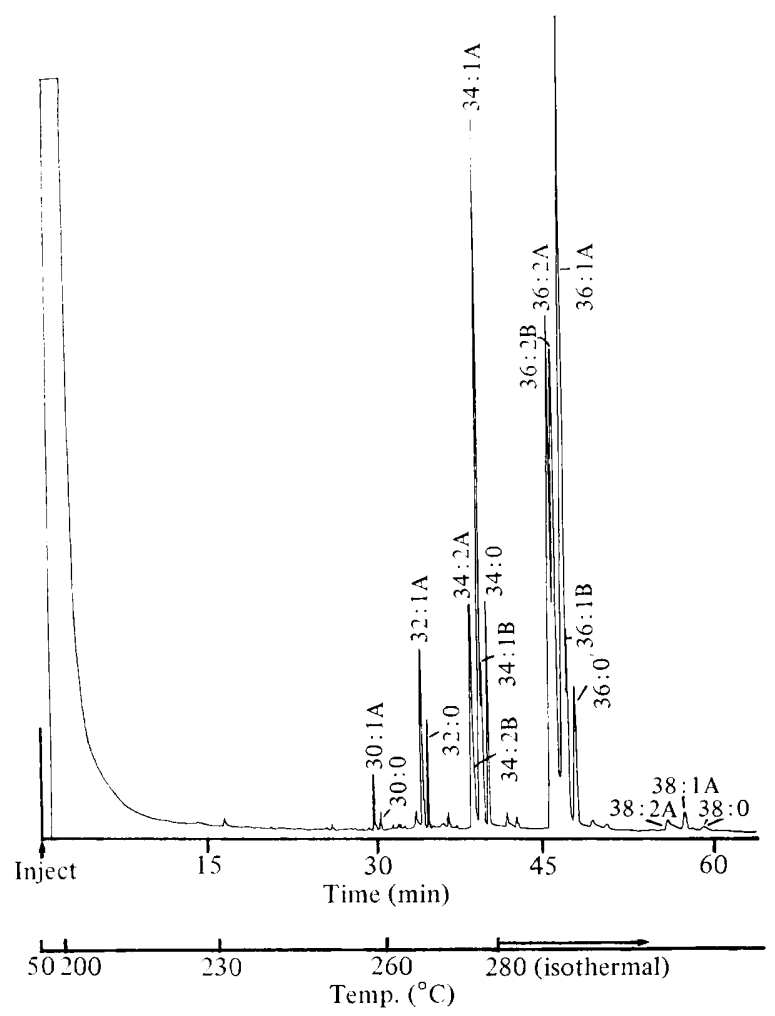

Fig. 1. Chromatogram of wax esters of Micrococcus cryophilus grown at $20^{\circ} \mathrm{C}$, analysed using the $20 \mathrm{~m}$ wall-coated open tubular capillary column (for details, see Methods). Wax esters are designated by 'number of carbon atoms: number of double bonds'. A and B refer to the $\Delta 9$ and $\Delta 11$ isomers, respectively, of mono-unsaturated wax esters, and to the major peaks of di-unsaturated wax esters.

and oleyl stearate co-elute. Compounds B are cis $\Delta 11$ wax esters. The di-unsaturated wax esters were resolved into two major peaks (A and B) and one minor peak (Fig. 1). Excluding the minor contributions from $\mathrm{C}_{14}$ and $\mathrm{C}_{20}$ fatty alcohols and fatty acids to $\mathrm{C}_{36}$ and $\mathrm{C}_{38}$ wax esters, it is believed that compounds $\mathrm{A}$ are $\Delta 9-\Delta 9$ di-unsaturated wax esters [using the shorthand notation of Aasen et al. (1971), in which the fatty alcohol precedes the fatty acid], compounds $\mathrm{B}$ are a mixture of $\Delta 9-\Delta 11$ and $\Delta 11-\Delta 9$ wax esters, and the minor compounds are $\Delta 11-\Delta 11$ wax esters.

\section{Wax ester fatty alcohol and fatty acid composition}

The major fatty alcohols and fatty acids of the wax esters were $\mathrm{C}_{18}$, with smaller amounts of $\mathrm{C}_{16}$ (Tables 2 and 3 ). The fatty alcohols were more saturated than the fatty acids; the ratio of saturated/unsaturated fatty alcohols in wax esters of bacteria grown at $20{ }^{\circ} \mathrm{C}$ was 0.94 , compared with a value of 0.48 for the fatty acids. The corresponding values of this ratio for fatty alcohols and fatty acids of wax esters in bacteria grown at $1{ }^{\circ} \mathrm{C}$ were $0 \cdot 11$ and $0 \cdot 08$, respectively. These values show that when the bacterial growth temperature was lowered the degree of unsaturation of both fatty alcohols and fatty acids increased. In contrast, there was less change in their chain length. The $\mathrm{C}_{18} / \mathrm{C}_{16}$ ratios of combined saturated and unsaturated fatty alcohols in wax esters of bacteria grown at 20 and $1{ }^{\circ} \mathrm{C}$, calculated from the results in Tables 2 and 3, were $4 \cdot 13$ and 3.45, respectively; the corresponding values for wax ester fatty acids were 4.64 and $4 \cdot 01$. These results also show that the average chain 


\section{Table 2. Percentage composition of fatty alcohols in wax esters of Micrococcus cryophilus} grown at 1 or $20^{\circ} \mathrm{C}$

See legend to Table 1 and Methods for details. Peaks of 12:1, 14:1 and 20:1 were too small a percentage of the total to be resolved accurately into $\Delta 9$ and $\Delta 11$ isomers; the total for each peak is given. The ratios of $\Delta 9$ to $\Delta 11$ isomers in $16: 1$ and $18: 1$ are represented by $16: 1, \Delta 9 / \Delta 11$ and $18: 1, \Delta 9 / \Delta 11$, respectively.

\begin{tabular}{|c|c|c|c|c|}
\hline \multirow[b]{2}{*}{ Fatty alcohol } & \multicolumn{2}{|c|}{ Growth at $1^{\circ} \mathrm{C}(n=2)$} & \multicolumn{2}{|c|}{ Growth at $20^{\circ} \mathrm{C}(n=3)$} \\
\hline & $\begin{array}{c}\text { Composition } \\
(\%)\end{array}$ & $18 / 16$ & $\begin{array}{c}\text { Composition } \\
(\%)\end{array}$ & $18 / 16$ \\
\hline $\begin{array}{c}\text { Saturated } \\
12: 0 \\
14: 0 \\
16: 0 \\
18: 0 \\
20: 0 \\
\text { Others }\end{array}$ & $\begin{array}{c}0 \cdot 1 \pm 0 \cdot 0 \\
0 \cdot 6 \pm 0 \cdot 3 \\
6 \cdot 6 \pm 3 \cdot 0 \\
2 \cdot 9 \pm 2 \cdot 3 \\
\text { tr } \\
\text { ND }\end{array}$ & & $\begin{array}{r}0.5 \pm 0.5 \\
1.7 \pm 0.6 \\
12 \cdot 9 \pm 2 \cdot 5 \\
31 \cdot 7 \pm 7 \cdot 2 \\
1.3 \pm 0.9 \\
\text { ND }\end{array}$ & \\
\hline Total saturated & $10 \cdot 2$ & $0 \cdot 44$ & $48 \cdot 1$ & $2 \cdot 46$ \\
\hline $\begin{array}{l}\text { Mono-unsaturated } \\
12: 1 \\
14: 1 \\
16: 1 \Delta 9 \\
16: 1 \Delta 11 \\
18: 1 \Delta 9 \\
18: 1 \Delta 11 \\
20: 1 \\
\text { Others }\end{array}$ & $\begin{array}{c}\text { ND } \\
0 \cdot 5 \pm 0 \cdot 2 \\
7 \cdot 7 \pm 1 \cdot 4 \\
7 \cdot 8 \pm 1 \cdot 9 \\
59 \cdot 9 \pm 5 \cdot 9 \\
13 \cdot 4 \pm 6 \cdot 5 \\
0 \cdot 1 \pm 0 \cdot 1 \\
0.5 \pm 0 \cdot 1\end{array}$ & & $\begin{array}{c}\text { ND } \\
0 \cdot 4 \pm 0 \cdot 2 \\
1 \cdot 7 \pm 0 \cdot 5 \\
3 \cdot 8 \pm 1 \cdot 9 \\
27 \cdot 3 \pm 2 \cdot 7 \\
17 \cdot 0 \pm 4 \cdot 9 \\
1 \cdot 2 \pm 1 \cdot 0 \\
0 \cdot 4 \pm 0 \cdot 0\end{array}$ & \\
\hline Total mono-unsaturated & $89 \cdot 9$ & $4 \cdot 73$ & $51 \cdot 8$ & $8 \cdot 06$ \\
\hline $\begin{array}{l}16: 1, \Delta 9 / \Delta 11 \\
18: 1, \Delta 9 / \Delta 11\end{array}$ & $\begin{array}{l}0.99 \\
4.47\end{array}$ & & $\begin{array}{l}0.45 \\
1.61\end{array}$ & \\
\hline
\end{tabular}

length of the wax ester fatty acids was slightly greater than that of the fatty alcohols, at both growth temperatures.

Capillary g.l.c. resolved the mono-unsaturated fatty alcohols and fatty acids into two components, which were identified as cis $\Delta 9$ and cis $\Delta 11$ isomers on the basis of their cochromatography with authentic standards on both polar and non-polar column coatings and several different chromatographic conditions. In addition, the isomers of $\mathrm{C}_{16: 1}$ and $\mathrm{C}_{18: 1}$ fatty alcohols and fatty acids were identified as cis, rather than trans, on the basis of their co-chromatography in the cis-unsaturated band on argentation t.l.c.; unsaturated isomers were not recovered from the saturated band with which potential trans isomers would have co-chromatographed (Morris, 1966). Infrared spectroscopy was also used to demonstrate the absence of trans isomers. The exclusion of trans isomers using an independent method was believed to be important, because in certain of the gas chromatographic systems used the cis $\Delta 11$ isomers co-eluted with trans $\Delta 9$ isomers. Typical infrared spectra of the wax esters of $M$. cryophilus and authentic stearyl oleate are shown in Fig. 2. Although di-unsaturated wax ester standards were not available, the spectra of $M$. cryophilus wax esters corresponded closely with those of cis-mono-unsaturated wax ester standards. As a check, the spectra of wax ester constituent fatty alcohols and fatty acids were compared directly with oleic acid, oleyl alcohol and elaidic acid standards. The absorption peaks at 2850 to $3000 \mathrm{~cm}^{-1}$, due to methyl and methylene deformation vibrations, are roughly constant amongst the $\mathrm{C}_{18}$ compounds used (Jart, 1960). Since the major fatty alcohols and fatty acids in $M$. cryophilus wax esters are $\mathrm{C}_{18}$, the 2850 to $3000 \mathrm{~cm}^{-1}$ absorption band could be used as an internal standard. In this way it was possible to record spectra of wax esters (Fig. 2), fatty alcohols and fatty acids under conditions that would have detected the 
Table 3. Percentage composition of fatty acids in wax esters of Micrococcus cryophilus grown at 1 or $20^{\circ} \mathrm{C}$

See legends to Tables 1 and 2 for details.

\begin{tabular}{|c|c|c|c|c|}
\hline \multirow[b]{2}{*}{ Fatty acid } & \multicolumn{2}{|c|}{ Growth at $1{ }^{\circ} \mathrm{C}(n=3)$} & \multicolumn{2}{|c|}{ Growth at $20 \mathrm{C}(n=3)$} \\
\hline & $\begin{array}{c}\text { Composition } \\
(\%)\end{array}$ & $18 / 16$ & $\begin{array}{c}\text { Composition } \\
(\%)\end{array}$ & $18 / 16$ \\
\hline $\begin{array}{c}\text { Saturated } \\
12: 0 \\
14: 0 \\
16: 0 \\
18: 0 \\
20: 0 \\
\text { Others }\end{array}$ & $\begin{array}{c}0 \cdot 5 \pm 0 \cdot 2 \\
0 \cdot 7 \pm 0 \cdot 5 \\
4 \cdot 8 \pm 1 \cdot 9 \\
1 \cdot 9 \pm 1 \cdot 2 \\
\text { ND } \\
\text { ND }\end{array}$ & & $\begin{array}{r}0.9 \pm 0.4 \\
1.9 \pm 0 \cdot 3 \\
13 \cdot 9 \pm 2 \cdot 0 \\
15 \cdot 2 \pm 2 \cdot 0 \\
0.4 \pm 0 \cdot 1 \\
\text { ND }\end{array}$ & \\
\hline Total saturated & $7 \cdot 9$ & $0 \cdot 40$ & $32 \cdot 3$ & 1.09 \\
\hline $\begin{array}{l}\text { Mono-unsaturated } \\
12: 1 \\
14: 1 \\
16: 1 \Delta 9 \\
16: 1 \Delta 11 \\
18: 1 \Delta 9 \\
18: 1 \Delta 11 \\
20: 1 \\
\text { Others }\end{array}$ & $\begin{array}{c}\text { ND } \\
\text { ND } \\
4 \cdot 0 \pm 1 \cdot 6 \\
10 \cdot 8 \pm 0 \cdot 5 \\
72 \cdot 7 \pm 0 \cdot 7 \\
4 \cdot 0 \pm 2 \cdot 4 \\
0 \cdot 1 \pm 0 \cdot 0 \\
0 \cdot 5 \pm 0 \cdot 1\end{array}$ & & $\begin{array}{c}\text { ND } \\
0 \cdot 1 \pm 0 \cdot 1 \\
2 \cdot 0 \pm 0 \cdot 3 \\
1 \cdot 1 \pm 0 \cdot 5 \\
57 \cdot 8 \pm 2 \cdot 8 \\
5 \cdot 8 \pm 0 \cdot 7 \\
0 \cdot 3 \pm 0 \cdot 3 \\
0 \cdot 7 \pm 0 \cdot 2\end{array}$ & \\
\hline Total mono-unsaturated & $92 \cdot 1$ & $5 \cdot 18$ & $67 \cdot 8$ & $20 \cdot 52$ \\
\hline $\begin{array}{l}16: 1, \Delta 9 / \Delta 11 \\
18: 1, \Delta 9 / \Delta 11\end{array}$ & $\begin{array}{r}0 \cdot 37 \\
18 \cdot 18\end{array}$ & & $\begin{array}{l}1 \cdot 82 \\
9 \cdot 97\end{array}$ & \\
\hline & ND, & & & \\
\hline
\end{tabular}

characteristic trans absorption at $962 \mathrm{~cm}^{-1}$ (Bellamy, 1958). Such an absorption was never detected in the samples from $M$. cryophilus, indicating the absence of trans isomers.

Additional support for the identification of the $\mathrm{C}_{18: 1}$ fatty alcohol and fatty acid isomers was provided by the determination of the position of the double bond by mild permanganate oxidation. G.l.c. analysis of the methylated dicarboxylic acid fragments of fatty alcohols and fatty acids revealed the presence of $\mathrm{C}_{9}$ and $\mathrm{C}_{11}$ dicarboxylic acid dimethyl esters in the ratios expected from the intact fatty alcohol and fatty acid capillary g.l.c. analyses. There was not enough material, however, to repeat such an analysis for the $\mathrm{C}_{16: 1}$ fatty alcohols and fatty acids, so that their designation as $\Delta 9$ and $\Delta 11$ positional isomers rests upon the capillary g.l.c. analysis only.

The results in Tables 2 and 3 showed that the proportions of $\Delta 9$ and $\Delta 11$ isomers differed markedly in the $C_{16: 1}$ and $C_{18: 1}$ components of both fatty alcohols and fatty acids; the $\Delta 9 / \Delta 11$ ratio of $C_{18: 1}$ was much higher than that of $C_{16: 1}$, irrespective of the growth temperature. The $\Delta 9 / \Delta 11$ ratio of the combined $C_{16}+C_{18}$ fatty acids $(5 \cdot 2$ to $8 \cdot 7: 1)$ was higher than that of the combined $\mathrm{C}_{16}+\mathrm{C}_{18}$ fatty alcohols $(1 \cdot 4$ to $3 \cdot 2: 1)$ throughout the growth temperature range. When the growth temperature was raised from 1 to $20{ }^{\circ} \mathrm{C}$ there was an increase in the proportion of $\Delta 11$ isomers in the $\mathrm{C}_{18: 1}$ fatty alcohols and fatty acids relative to both $\mathrm{C}_{18: 1} \Delta 9$ and total fatty alcohol or fatty acid contents. It was difficult to draw corresponding conclusions regarding the relative proportions of $\Delta 9$ and $\Delta 11$ isomers of $\mathrm{C}_{16: 1}$ in bacteria grown at $20^{\circ} \mathrm{C}$, due to the small amounts of $\mathrm{C}_{16: 1}$ fatty alcohols and fatty acids produced at this temperature. 


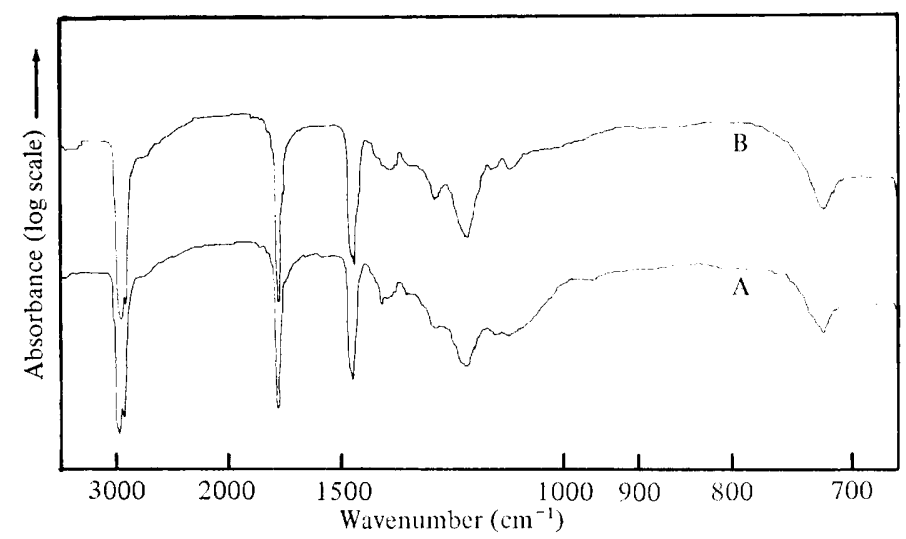

Fig. 2. Typical infrared spectra of wax esters of Micrococcus cryophilus grown at $20^{\circ} \mathrm{C}$ (A) and of stearyl oleate (B). Infrared spectra were obtained using thick films in $\mathrm{NaCl}$ cells as detailed in Methods.

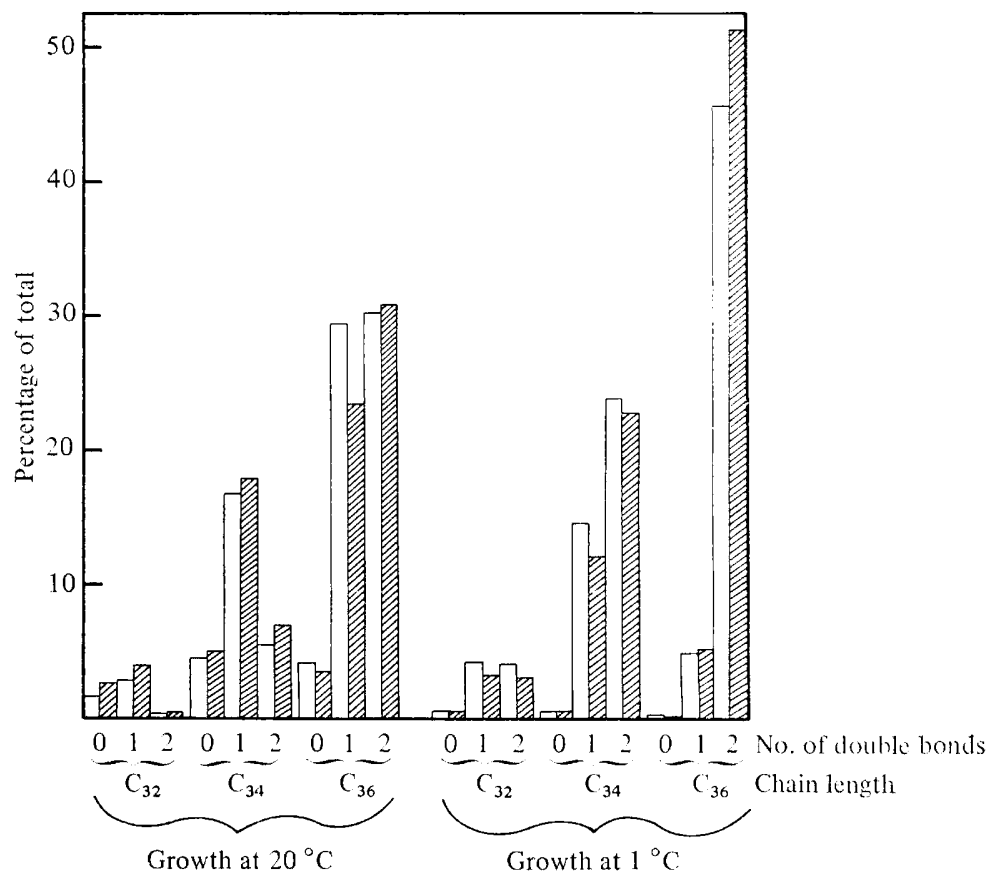

Fig. 3. Comparison of the observed and calculated random wax ester profiles of Micrococcus cryophilus grown at 20 or $1{ }^{\circ} \mathrm{C}$. The composition of wax esters of M. cryophilus as measured by capillary g.l.c. ( $\square$ ) is compared with the wax ester composition calculated by assuming a random combination of the fatty alcohol and fatty acids prepared by saponification of the same wax ester sample $(\mathbb{Z})$. For the purposes of calculating the random composition the values of $\Delta 9$ and $\Delta 11$ isomers have been combined for each particular chain length. To make comparisons easier, results are shown for the major wax ester chain lengths only; these accounted for about $95 \%$ of the total wax esters. 


\section{Relationship of fatty alcohol and fatty acid composition to wax ester composition}

The fact that the major fatty alcohols and fatty acids were $\mathrm{C}_{18}$, with smaller amounts of $\mathrm{C}_{16}$, together accounted for the pattern of chain lengths of the intact wax esters, in which $\mathrm{C}_{36}$ predominated with smaller amounts of $\mathrm{C}_{34}$ and $\mathrm{C}_{32}$. The observed wax ester distribution was due, apparently, to a random combination of fatty alcohols and fatty acids, both in terms of the chain length distribution within the saturated, mono-unsaturated and diunsaturated classes, and the relative amounts of each class (Fig. 3). The largest discrepancy between theoretical and observed frequencies was in the $\mathrm{C}_{34: 1}$ and $\mathrm{C}_{36: 1}$ wax esters; otherwise, the values corresponded closely for wax esters of bacteria grown at 1 or $20^{\circ} \mathrm{C}$.

\section{Melting points of mono-unsaturated wax esters}

The melting points of three isomers of $\mathrm{C}_{36: 1}$ wax esters were: for stearyl palmitoleate (18:0-16:1), $29 \cdot 5^{\circ} \mathrm{C}$; for oleyl palmitate $(18: 1-16: 0), 31^{\circ} \mathrm{C}$; for palmityl oleate (16:0-18:1), $20 \cdot 5^{\circ} \mathrm{C}$. Unfortunately no authentic sample of palmitoleyl stearate $(16: 1-18: 0)$ was available.

\section{DIS CUSSION}

The present paper confirms and extends previously published data on the wax ester fatty alcohol and fatty acid compositions of Micrococcus cryophilus obtained using different g.l.c. conditions (Russell, 1978 a), as well as providing new, detailed information about wax ester compositional changes related to growth temperature. There are only a few examples of the use of capillary g.l.c. to study wax ester composition, and the technique has not been used previously to study bacterial wax esters; the potential of the technique is exemplified by the novel discovery of double bond positional isomers of wax ester unsaturated fatty alcohols and fatty acids.

Wax ester analysis has been used as an aid in the classification of strains of the family Neisseriaceae by Bryn et al. (1977) who showed that the wax esters of Acinetobacter spp. contained a much higher proportion of di-unsaturated wax esters (30 to $98 \%$ of the total) than did 'false neisseriae' and Moraxella spp. ( $\leqslant 8 \%$ of the total). Micrococcus cryophilus is a Gram-negative coccus and resembles Acinetobacter spp. in some respects (Russell, 1974) but not in others (Juni, 1972; Jantzen et al., 1975). It may be significant, therefore, that $M$. cryophilus contains a high proportion of di-unsaturated wax esters ( 41 to $84 \%$ of the total) throughout its growth temperature range.

Wax esters represent a significant proportion of the lipid in cellular membranes of $M$. cryophilus (Russell, 1974). Thus, the growth temperature-dependent changes in chain length and unsaturation of wax esters may be important factors in the control of membrane fluidity in this bacterium. As the growth temperature was decreased the wax esters became more unsaturated and their average chain length decreased. Both effects would serve to maintain membrane fluidity at the lower growth temperature (Lee, 1975; Chapman \& Wallach, 1968). However, the interpretation may not be so simple. Firstly, at any one growth temperature the chain length of the mono-unsaturated wax esters was relatively shorter than that of the di-unsaturated wax esters, which would tend to reduce the difference in their melting points and thus minimize differences in their effect on membrane fluidity. Secondly, the melting point of mono-unsaturated wax esters depends on whether the double bond is in the fatty alcohol or fatty acid moiety, as well as the chain length of the moiety containing the double bond; the melting point of a cis-mono-unsaturated wax ester is lower when the double bond is in the fatty acid than when it is in the fatty alcohol. For example, if isomers of $\mathrm{C}_{36: 1}$ wax esters are considered, the melting point of stearyl palmitoleate $(18: 0-16: 1)$ is $1.5{ }^{\circ} \mathrm{C}$ lower than that of oleyl palmitate $(18: 1-16: 0)$. An even greater effect on the melting point is observed when the relative chain length of the fatty alcohol and fatty acid are changed. Thus, the melting point of palmityl oleate $(16: 0-18: 1)$ is $10 \cdot 5^{\circ} \mathrm{C}$ lower 
than that of oleyl palmitate $(18: 1-16: 0)$. The isomeric composition of each wax ester is therefore of crucial importance in determining its contribution to membrane fluidity, particularly since the melting points span the growth temperature range.

When the fatty alcohol and fatty acid compositions were used to generate a theoretical random wax ester mixture the composition obtained corresponded closely to that observed for intact wax esters, suggesting that specific fatty alcohol-fatty acid combinations do not occur. Similar random combinations of fatty alcohols and fatty acids have been suggested for the wax esters of the surface lipids of Pisum leaves (Kolattukudy, 1970) and in some marine organisms (Nevenzel, 1970) but not others (Iyengar \& Schlenk, 1967). However, it is possible that, in $M$. cryophilus, in addition to the overall changes in wax ester chain length and degree of unsaturation, membrane fluidity might be regulated by alterations in the combinations of fatty alcohols and fatty acids in mono-unsaturated wax esters, which represent 15 to $50 \%$ of the total wax esters. Such changes could be investigated by determining the fatty alcohol and fatty acid composition of individual wax esters. This is currently being studied using capillary g.l.c./mass spectrometry. It is not known what effect the presence of significant amounts of cis $\Delta 11$ isomers, in the fatty alcohols in particular, will have on wax ester fluidity, since there are no physicochemical data available for comparison.

The presence of $c i s \Delta 11$ isomers poses some interesting questions about the biosynthesis of wax esters. It is assumed that, since $M$. cryophilus synthesizes unsaturated fatty acids using an aerobic $\Delta 9$ desaturase (Russell, $1978 \mathrm{~b}$ ), the $\Delta 11$ isomers must be synthesized by elongation of $\Delta 9$ isomers. This elongation system obviously must use an unsaturated substrate, presumably acyl-CoA, in contrast to the elongation system believed to be responsible for the modification of phospholipid acyl chain length (Russell \& Sandercock, 1980), which uses a saturated substrate, because phospholipid acyl chains are almost exclusively cis $\Delta 9$ isomers (Russell, 1978 b). The wax ester fatty alcohols contain a higher proportion of $\Delta 11$ isomers relative to $\Delta 9$ isomers than do the wax ester fatty acids. The basis of this difference may reside in the specificity of either the acyl-CoA reductase or the wax ester synthetase, which would synthesize and esterify, respectively, cis $\Delta 11$ fatty alcohols in preference to cis $\Delta 9$ fatty alcohols. It will be of interest, therefore, to isolate the enzymes of wax ester synthesis and to study properties such as the effect of temperature on their substrate specificity.

J.K.V. gratefully acknowledges the financial assistance of the Natural Environment Research Council, grant number GR3/3419. Gas chromatography/mass spectrometry facilities were funded by NERC grant number GR3/2951. N.J.R. would like to thank Professor G. Eglinton for kindly providing laboratory facilities.

\section{REFERENCES}

Aasen, A. J., Hofstetter, H. H., Iyengar, B. T. R. \& Holman, R. T. (1971). Identification and analysis of wax esters by mass spectrometry. Lipids 6, 502-507.

Albro, P. W. (1976). In Chemistry and Biochemistry of Natural Waxes, pp. 419-422. Edited by P. E. Kolattukudy. Amsterdam: Elsevier.

Bellamy, L. J. (1958). The Infra-red Spectra of Complex Molecules, 2nd edn. London: Methuen.

Boon, J. J. \& DE Leeuw, J. W. (1979). The analysis of wax esters, very long mid-chain ketones and sterolethers isolated from Walvis Bay diatomaceous ooze. Marine Chemistry 7, 117-132.

Bryn, K., JanTZEN, E. \& BøVRE, K. (1977). Occurrence and patterns of waxes in Neisseriaceae. Journal of General Microbiology 102, 33-43.
Chapman, D. \& Wallach, D. F. H. (1968). Recent physical studies of phospholipids and natural membranes. In Biological Membranes. Physical Fact and Function, pp. 125-202. Edited by D. Chapman. London: Academic Press.

Day, J. I. E., Goldfine, H. \& Hagen, P.-O. (1970). Enzymic reduction of long-chain acyl-CoA to fatty aldehyde and alcohol by extracts of Clostridium butyricum. Biochimica et biophysica acta 218, 179-182.

Downing, D. T. \& Greene, R. S. (1968). Rapid determination of double-bond positions in monoenoic fatty acids by periodate-permanganate oxidation. Lipids 3, 96-100.

Fixter, L. M. \& Fewson, C. A. (1974). The accumulation of waxes by Acinetobacter calco- 
aceticus N.C.I.B. 8250. Biochemical Society Transactions 2, 944-945.

GallaGHER, I. H. C. (1971). Occurrence of waxes in Acinetobacter. Journal of General Microbiology 68, 245-247.

Grob, K., JR, Grob, G. \& Grob, K. (1978). Preparation of apolar glass capillary columns by the barium carbonate procedure. Journal of High Resolution Chromatography and Chromatography Communications 1, 149-155.

IYENGAR, R. \& SCHLENK, H. (1967). Wax esters of mullet (Mugil cephalus) roe oil. Biochemistry 6, 396-402.

Jantzen, E., Bryn, K., Bergan, T. \& Bøvre, K. (1975). Gas chromatography of bacterial whole cell methanolysates. VII. Fatty acid composition of Acinetobacter in relation to the taxonomy of Neisseriaceae. Acta pathologica et microbiologica scandinavica B83, 569-580.

JART, A. (1960). The infrared absorption spectra of some mono-unsaturated and saturated fatty acids and esters. Acta chemica scandinavica 14, 18671878.

JUNI, E. (1972). Interspecies transformation of Acinetobacter: genetic evidence for a ubiquitous gene. Journal of Bacteriology 112, 917-931.

Kolattukudy, P. E. (1970). Composition of the surface lipids of pea leaves (Pisum sativum). Lipids 5, 398-402.

Kolattukudy, P. E. (editor) (1976). Chemistry and Biochemistry of Natural Waxes. Amsterdam: Elsevier.

LEE, A. G. (1975). Functional properties of biological membranes: a physical chemical approach. Progress in Biophysics and Molecular Biology 29, $3-56$.

Makula, R. A., Lockwood, P. J. \& Finnerty, W. R. (1975). Comparative analysis of the lipids of Acinetobacter species grown on hexadecane. Journal of Bacteriology 121, 250-258.

MorRIS, L. J. (1966). Separation of lipids by silver ion chromatography. Journal of Lipid Research 7 , 717-732.

Naccarato, W. F., Gelman, R. A., Kawalek, J. C. \& GilberTSON, J. R. (1972). Characterisation and metabolism of free fatty alcohols from Escherichia coli. Lipids 7, 275-281.
Naccarato, W. F., Gilbertson, J. R. \& Gelman, R. A. (1974). In vivo and in vitro biosynthesis of free fatty alcohols in Escherichia coli K-12. Lipids 9, 419-428.

Nevenzel, J. C. (1970). Occurrence, function and biosynthesis of wax esters in marine organisms. Lipids 5, 308-319.

RusSELl, N. J. (1974). The lipid composition of the psychrophilic bacterium Micrococcus cryophilus. Journal of General Microbiology 80, 217-225.

Russell, N. J. (1978a). A differential effect of growth temperature on the phospholipid and neutral lipid fatty acyl composition of Micrococcus cryophilus. FEMS Microbiology Letters 4, 335338.

RuSSELL, N. J. (1978b). The positional specificity of a desaturase in the psychrophilic bacterium Micrococcus cryophilus (ATCC 15174). Biochimica et biophysica acta 531, 179-186.

Russell, N. J. \& SANDerCock, S. P. (1980). Control of membrane fluidity by fatty acid elongation. In Proceedings of the Symposium on Control of Membrane Fluidity. New Jersey: Humana Press. (In the Press.)

SPENCER, G. F. (1979). Alkoxy-acyl combinations in the wax esters from winterized sperm whale oil by gas chromatography mass spectrometry. Journal of the American Oil Chemists' Society 56, 642-646.

Tagaki, T., Itabashi, Y., OTa, T. \& Hayashi, K. (1976). Gas chromatographic separation of wax esters based on the degree of unsaturation. Lipids 11, 354-356.

Thorne, K. J. I., Thornley, M. J. \& Glauert, A. M. (1973). Chemical analysis of the outer membrane and other layers of the cell envelope of Acinetobacter sp. Journal of Bacteriology 116, 410-417.

Tulloch, A. P. (1975). Chromatographic analysis of natural waxes. Journal of Chromatographic Science 13, 403-407.

Wang, L., Takayama, K., Goldman, D. S. \& SchNoEs, H. K. (1972). Synthesis of alcohol and wax ester by a cell-free system in Mycobacterium tuberculosis. Biochimica et biophysica acta 260, $41-48$. 